\title{
The potential of magnetisation transfer NMR to monitor the dissolution process of cellulose in cold alkali
}

\author{
Maria Gunnarsson • Merima Hasani · Diana Bernin (1)
}

Received: 16 June 2019/Accepted: 3 September 2019/Published online: 12 September 2019

(C) The Author(s) 2019

\begin{abstract}
Cellulose is the most important biopolymer on earth and, when derived from e.g. wood, a promising alternative to for example cotton, which exhibits a large environmental burden. The replacement depends, however, on an efficient dissolution process of cellulose. Cold aqueous alkali systems are attractive but these solvents have peculiarities, which might be overcome by understanding the acting mechanisms. Proposed dissolution mechanisms are for example the breakage of hydrophobic interactions and partly deprotonation of the cellulose hydroxyl groups. Here, we performed a mechanistic study using equimolar aqueous solutions of $\mathrm{LiOH}, \mathrm{NaOH}$ and $\mathrm{KOH}$ to elucidate the dissolution process of microcrystalline cellulose (MCC). The $\mathrm{pH}$ was the highest
\end{abstract}

M. Gunnarsson · M. Hasani

Division of Forest Products and Chemical Engineering, Department of Chemistry and Chemical Engineering, Chalmers University of Technology,

SE-412 96 Gothenburg, Sweden

\section{Hasani}

Wallenberg Wood Science Center, The Royal Institute of Technology, Chalmers University of Technology,

SE-100 44 Stockholm, Sweden

D. Bernin $(\square)$

Division of Chemical Reaction Engineering, Department of Chemistry and Chemical Engineering, Chalmers

University of Technology, SE-412 96 Gothenburg,

Sweden

e-mail: diana.bernin@chalmers.se for $\mathrm{KOH}(\mathrm{aq})$ followed by $\mathrm{NaOH}(\mathrm{aq})$ and $\mathrm{LiOH}(\mathrm{aq})$. We used a combination of conventional and advanced solution-state NMR methods to monitor the dissolution process of MCC by solely increasing the temperature from -10 to $5{ }^{\circ} \mathrm{C}$. $\mathrm{KOH}(\mathrm{aq})$ dissolved roughly $25 \%$ of the maximum amount of MCC while $\mathrm{NaOH}(\mathrm{aq})$ and $\mathrm{LiOH}(\mathrm{aq})$ dissolved up to $70 \%$. Water motions on nanoscale timescales present in non-frozen water, remained unaffected on the addition of MCC. Magnetisation transfer (MT) NMR experiments monitored the semi-rigid MCC as a function of temperature. Interestingly, although $\mathrm{NaOH}(\mathrm{aq})$ and $\mathrm{LiOH}(\mathrm{aq})$ were able to dissolve a similar amount at $5{ }^{\circ} \mathrm{C}$, MT spectra revealed differences with increasing temperature, suggesting a difference in the swollen state of $\mathrm{MCC}$ in $\mathrm{LiOH}(\mathrm{aq})$ already at $-10{ }^{\circ} \mathrm{C}$. Furthermore, MT NMR shows a great potential to study the water exchange dynamics with the swollen and semi-rigid MCC fraction in these systems, which might give valuable insights into the dissolution mechanism in cold alkali.

Keywords Cellulose - Dissolution · Alkali - NMR · Magnetisation transfer $\cdot \mathrm{pH}$ 


\section{Introduction}

Dissolution of cellulose is an important process for the production of for example textile fibres, barriers, filters etc. The amphiphilic character of the polymer, which associates through both intra- and intermolecular hydrogen bonds and hydrophobic interactions, is though a limiting factor in finding solvents capable of dissolving cellulose (Lindman et al. 2010; Medronho et al. 2012; Medronho and Lindman 2014). A number of options have been reported to be efficient such as molten organic salts and aqueous complexing agents (Liebert 2010). The properties of the final cellulosebased product are highly dependent on the dissolution efficiency of cellulose on a molecular level, i.e. if the cellulose chains are aggregated, swollen or separated. One of the most environmentally friendly dissolution systems for cellulose, although not yet commercially implemented, is cold aqueous metal alkalis. The ability of $\mathrm{NaOH}(\mathrm{aq})$ to dissolve cellulose was found already in the beginning of the 1920's by Lilienfeld (1924) and was thereafter studied for several aqueous metal alkalis more in detail by Davidson (1934). Even though these solvent systems utilise chemicals familiar to the pulp and paper industry and therefore should be easy to implement in a commercial process, the problem of generating stable solutions has been a major obstacle. A stable solution refers to the ability of the cellulose chains to remain dissolved without any physical changes such as gelation or precipitation, and is a main criterion for the production of textile fibers and film to obtain high quality properties during coagulation of the dissolved cellulose chains. The reason for this instability is the narrow dissolution window at a specific concentration of $\mathrm{NaOH}(\mathrm{aq})$ and a certain temperature, namely around $2.0 \mathrm{M}$ and $-5{ }^{\circ} \mathrm{C}$ (Sobue et al. 1939). The ability to widen the dissolution window and thus maintain a more stable solution has been shown possible through the addition of for example urea, thiourea and $\mathrm{ZnO}$ (Cai and Zhang 2005; Yang et al. 2011; Zhou et al. 2004; Zhang et al. 2002). The complex, although fascinating, dissolution mechanism for cellulose in $\mathrm{NaOH}(\mathrm{aq})$ has still no definite explanation although many hypotheses have been developed, which includes partial deprotonation of the hydroxyl groups and hydration shells around the ions as driving forces (Bialik et al. 2016; Budtova and Navard 2016).
A comparison of the dissolution capacity of different aqueous metal alkalis based on wt $\%$ might be misleading, especially when combined with an additive based on wt $\%$ because the number of ionic species will differ. In addition, the properties of the solvent systems such as $\mathrm{pH}$ and activity coefficients might be different. Due to different pKb's of the aqueous metal alkalis, this is of special importance for concentrated solutions. Notably, the addition of urea was recently found to increase the $\mathrm{pH}$ of a $\mathrm{NaOH}(\mathrm{aq})$ (Gunnarsson et al. 2019). Hence, in order to draw valid conclusions towards a possible mechanism or mechanisms, careful considerations of how to compare these solvents are crucial.

Nevertheless, swelling is believed to be the first step to dissolution and the interaction with water during this process seems to play an important role (Budtova and Navard 2016). There is, however, a lack of experimental techniques to monitor the swelling of cellulose without disturbing the cellulose structure by shearing or filtering, a requirement for light scattering techniques. Hence, in this work, we compared the dissolution process of microcrystalline cellulose (MCC) in equimolar $\mathrm{LiOH}(\mathrm{aq}), \mathrm{NaOH}(\mathrm{aq})$ and $\mathrm{KOH}(\mathrm{aq})$ solutions at $-10,-5$ and $5{ }^{\circ} \mathrm{C}$ using NMR spectroscopy by solely increasing the temperature. The amount of dissolved cellulose was estimated from $1 \mathrm{D}{ }^{1} \mathrm{H}$ NMR spectra and confirmed by ${ }^{13} \mathrm{C}$ NMR. Gustavsson et al. (2014) and Alves et al. (2016) employed recently polarisation transfer NMR from ${ }^{13} \mathrm{C}$ to ${ }^{1} \mathrm{H}$ to elucidate the solid and dissolved state of cellulose in various solvent systems, while we herein applied magnetisation transfer (MT) NMR to monitor the semi-rigid swollen cellulose and associated water exchange dynamics. We observed differences in MT spectra with increasing temperature and solvent system and want to highlight the potential of MT NMR to report on the swollen state of cellulose, which might give additional clues to understand the dissolution mechanism in cold aqueous alkali.

\section{Materials and methods}

Materials

Microcrystalline cellulose (MCC) Avicel PH-101, with a degree of polymerisation of 260 , was purchased 
from FMC BioPolymer and used without further treatment. $\mathrm{LiOH}(>98 \%)$ and $\mathrm{KOH}(>85 \%)$ were purchased from Merck. $\mathrm{NaOH}(<98 \%)$ and $\mathrm{D}_{2} \mathrm{O}$ (99.9\%) were purchased from Sigma Aldrich. Urea (99\%) was purchased from VWR. All chemicals were used without further purification.

\section{Sample preparation}

An appropriate amount of MCC to give in total $0.4 \mathrm{M}$ was weighed into a $5 \mathrm{~mm}$ NMR tube and $500 \mu \mathrm{L}$ aqueous $2.0 \mathrm{M} \mathrm{LiOH}, \mathrm{NaOH}, \mathrm{KOH}$ or $\mathrm{NaOH} / 2.5 \mathrm{M}$ urea containing $80 \% \mathrm{D}_{2} \mathrm{O}$ was added on top. The mixture was then blended rigorously in the NMR tube during a couple of minutes using a vortex mixer until it appeared as a visually homogeneous suspension, i.e. when all MCC in the bottom of the NMR tube was observed as mixed with the solvent. The sample was immediately transferred to the freezer at $-20{ }^{\circ} \mathrm{C}$ and kept there until the start of the NMR experiments. The spectrometer was set to -15 or $-10{ }^{\circ} \mathrm{C}$ before inserting the NMR tube. Reference solutions were aqueous $2.0 \mathrm{M} \mathrm{LiOH}, \mathrm{NaOH}$ or $\mathrm{KOH}$ without the addition of MCC.

\section{$\mathrm{pH}$}

The $\mathrm{pH}$ measurements were carried out by pre-cooling the reference solutions with a concentration of $0.5 \mathrm{M}$ at $10{ }^{\circ} \mathrm{C}$. The concentration was reduced to avoid exceeding the measurable maximum with our setup, which is 14 , and compensate for the temperature dependency, which results in a larger $\mathrm{pH}$ with decreasing temperature. The $\mathrm{pH}$ was measured using a $\mathrm{HACH}$ HQ430D Multimeter with an Intellical PHC705A1 pH probe.

\section{NMR}

The NMR experiments were recorded on a $11.74 \mathrm{~T}$ (600 MHz) Bruker Avance III HD equipped with a diffusion probe fitted with a $5 \mathrm{~mm}{ }^{1} \mathrm{H}$ radio frequency (RF) insert. The spin-lattice relaxation time $T_{1}$ was estimated from inversion-recovery experiments with 16 variable delays $t$ from 0.1 up to $5 \mathrm{~s}$ and the spin-spin relaxation time $T_{2}$ from CPMG experiments with an echo spacing of $1.5 \mathrm{~ms}$, resulting in the longest echo time et of $380 \mathrm{~ms}$. The spin-lattice relaxation rates $R_{1}$ were calculated by $1 / T_{1}$. The $T_{1}$ was obtained by regressing the signal intensity $I$ versus $t$ in each Fourier transformed point of the spectrum to $I=I_{0}(1-a *$ $\left.\exp \left(-t / T_{1}\right)\right)$ and for the $T_{2}$ versus et to $I=I_{0} *$ $\exp \left(-e t / T_{2}\right)$ where $I_{0}$ is the non-weighted signal intensity at $t=0$ or $e t=0 . a$ is a pre-exponential factor, which for an inversion-recovery sequence should be close to 2 . We used a mono-exponential fitting albeit some signal decays or build-ups revealed a slightly curved decay in the semilogarithmic representation. Hence, the estimated relaxation times/rates represent mean values based on a cut-off of 0.94 for the ratio of the sum of squares of the regression and the total sum of squares.

$1 \mathrm{D}{ }^{1} \mathrm{H}$ spectra were recorded with a repetition delay of $20 \mathrm{~s}$ to enable a quantitative comparison. MT experiments were recorded with 128 frequency steps starting from -88.3 up to $83.3 \mathrm{ppm}$. Smaller steps were chosen close to the water peak and larger steps further away from the water peak. The duration of RF pulse for the saturation was $2 \mathrm{~s}$ with a $B_{1}$ field of 1580 Hz. A MT spectrum also denoted $Z$-spectrum represents the signal intensity of the water peak as a function of the saturation frequency in ppm. The intensity is normalised by the maximum intensity.

This setup of experiments were run at $-15,{ }^{1}-10$, -5 and $5{ }^{\circ} \mathrm{C}$. After stabilisation of the set temperature, the sample was allowed to rest for additional 15 min prior to the start of the NMR experiments.

The ${ }_{1 D}{ }^{13} \mathrm{C}$ NMR spectra experiments were recorded on an $18.8 \mathrm{~T}(800 \mathrm{MHz})$ magnet with a Bruker Avance III HD console and a TXO cryoprobe. The samples were prepared in the same manner as described above but in a $3 \mathrm{~mm}$ NMR tube. A single excitation pulse sequence with proton decoupling was applied with a repetition delay of $5 \mathrm{~s}$.

\section{Results and discussion}

There has been large debate on possible dissolution mechanisms of cellulose in various solvent systems (Lindman et al. 2010). One of the hypotheses about the cold aqueous metal alkali system is that cellulose turns into a polyelectrolyte due to deprotonation of the hydroxyl groups on cellulose. Bialik et al. reported

\footnotetext{
$\overline{1}$ Only measured for a few samples.
} 
recently on the partial deprotonation of the $\mathrm{C} 2$ carbon in cellobiose in this solvent using a combination of experimental ${ }^{1} \mathrm{H}$ and ${ }^{13} \mathrm{C}$ chemical shifts and DFT calculations (Bialik et al. 2016).

If deprotonation would be the sole mechanism for dissolution, the higher the $\mathrm{pH}$ of the solvent, the more efficient the dissolution of MCC would be. However, solutions at $>0.1 \mathrm{M}$ are inherently intricate because the concentration is beyond instrument limitations and applicable theories. Hence it is not obvious that a higher alkali concentration would lead to higher $\mathrm{pH}$, greater deprotonation and/or the dissolution of cellulose, which is also described in the phase diagram by Sobue et al. (1939). Still, the pH of the solvent is of interest for the understanding of the dissolution mechanism of cellulose in aqueous metal alkalis as it reflects on the activity of $\mathrm{H}^{+}$and charges present in the system but has, to our knowledge, not been elaborated on yet. Thus, we here elucidated on the actual difference in $\mathrm{pH}$ of the three reference solutions $\mathrm{LiOH}(\mathrm{aq}), \mathrm{NaOH}(\mathrm{aq})$ and $\mathrm{KOH}(\mathrm{aq})$ at equimolar concentration estimated to be within the detectable range of the $\mathrm{pH}$ electrode, namely $0.5 \mathrm{M}$ at $10{ }^{\circ} \mathrm{C}$, because $\mathrm{pH}$ is in addition temperature dependent. Although the alkali concentration and temperature are not equivalent to the conditions necessary for dissolution of cellulose, a relative comparison of the three solvents and their actual difference could provide valuable insight into the true solvent system.

Interestingly, the measurement showed that the $\mathrm{pH}$ of $\mathrm{KOH}(\mathrm{aq})$ was outside of the measurable region i.e. above 14 while the $\mathrm{pH}$ of $\mathrm{LiOH}(\mathrm{aq})$ and $\mathrm{NaOH}(\mathrm{aq})$ was 13.67 and 13.96 , respectively (Table 1 ), which clearly describes the difference in activity of the three solvents. According to the CRC Handbook of Chemistry and Physics, the pKa for $\mathrm{Na}^{+}$and $\mathrm{Li}^{+}$at $25{ }^{\circ} \mathrm{C}$ is 14.8 and 13.8, respectively, which also further is in agreement with literature reporting on $\mathrm{KOH}$ being the

Table 1 The $\mathrm{pH}$ of aqueous reference alkali solutions at $0.5 \mathrm{M}$ and $10{ }^{\circ} \mathrm{C}$

\begin{tabular}{lc}
\hline Sample & $\mathrm{pH}$ \\
\hline $\mathrm{LiOH}$ & 13.67 \\
$\mathrm{NaOH}$ & 13.96 \\
$\mathrm{KOH}$ & $>14$ \\
\hline
\end{tabular}

strongest base (Tata 1980). Although, the $\mathrm{pH}$ differences at $0.5 \mathrm{M}$ are small, we want to stress that the $\mathrm{pH}$ at $2.0 \mathrm{M}$, a pre-requisite to dissolve cellulose, is close to the $\mathrm{pKa}$ of the alkalis and $\mathrm{MCC}$, at which small $\mathrm{pH}$ differences result in significant changes in the amount of charged species.

Taken together, deprotonation as the sole mechanism for dissolution of cellulose would from these results suggest $\mathrm{KOH}(\mathrm{aq})$ to be the best solvent for cellulose.

\section{Dissolved cellulose}

The normalised integrals of the MCC peak obtained from 1D ${ }^{1} \mathrm{H}$ NMR spectra established the contrary (Fig. 1). At $5{ }^{\circ} \mathrm{C}, \mathrm{KOH}(\mathrm{aq})$ dissolved roughly $25 \%$ of the maximum amount of MCC (yellow dashed line), which is in accord with earlier reported results by Davidson (1937) but disagrees with results reported by Xiong et al. (2013) and Cai and Zhang (2005). In $\mathrm{NaOH}(\mathrm{aq})$ and $\mathrm{LiOH}(\mathrm{aq})$, more than $70 \%$ MCC dissolved at $5{ }^{\circ} \mathrm{C}$. This result is in agreement with the observations from Alves et al. (2016), who reported on a remaining solid MCC fraction in the $\mathrm{NaOH}(\mathrm{aq})$ system using $10 \% \mathrm{MCC}$ while we used $6.5 \%$. Furthermore, employing static light scattering

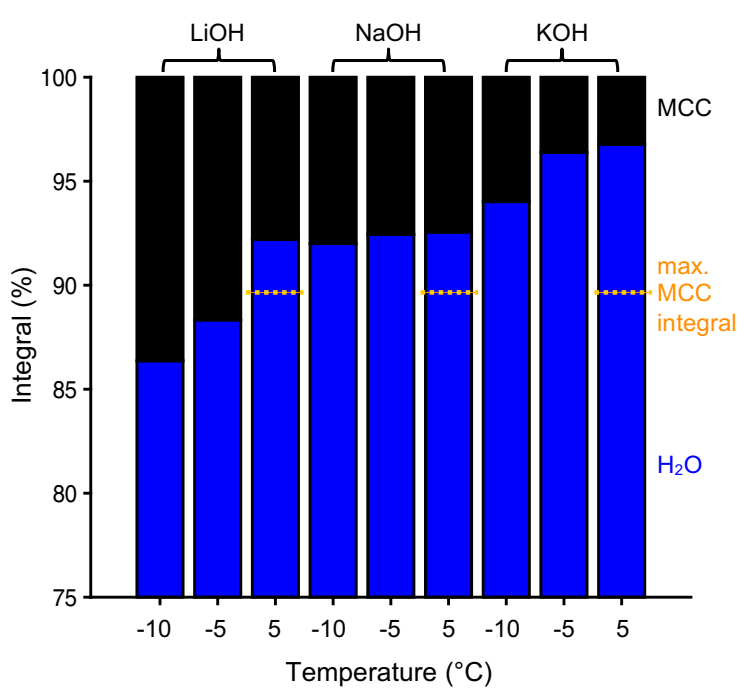

Fig. 1 Normalised integrals for MCC (black) and the water peak (blue) at $-10,-5$ and $5{ }^{\circ} \mathrm{C}$ estimated from $1 \mathrm{D}{ }^{1} \mathrm{H}$ NMR spectra normalised by the total amount of signal. Highlighted in yellow (dashed line) is the maximum amount of dissolved MCC based on the known amounts of MCC 
(Hagman et al. 2017), micrometer-sized aggregates were found when dissolving $1 \% \mathrm{MCC}$ in $\mathrm{NaOH}(\mathrm{aq})$.

The observable ${ }^{1} \mathrm{H}$ signals arise from non-frozen and NMR-detectable water and dissolved MCC. A ${ }^{1} \mathrm{H}$ spectrum for $\mathrm{LiOH}(\mathrm{aq})$ with the addition of $\mathrm{MCC}$ recorded at $5{ }^{\circ} \mathrm{C}$ is shown in Fig. 6a. In this representation, the water peak was set to $0 \mathrm{ppm}$, which shifts the clearly visible MCC peaks to negative ppm values.

From Fig. 1, it appears that a larger amount of MCC dissolved in $\mathrm{LiOH}(\mathrm{aq})$ at both -10 and $-5{ }^{\circ} \mathrm{C}$ compared to $\mathrm{NaOH}(\mathrm{aq})$ and $\mathrm{KOH}(\mathrm{aq})$ because the MCC integral (black) is larger. The mark (yellow dashed line) highlights the maximum MCC integral value corresponding to the dissolution of all added MCC. In case for $\mathrm{LiOH}(\mathrm{aq})$, the measured MCC integral of dissolved MCC exceeds the maximum amount at these temperatures. It is therefore suggested that this solvent, rather than being a better solvent for cellulose, has a lower amount of NMR-detectable $\mathrm{H}_{2} \mathrm{O}$, i.e. a lower amount of $\mathrm{H}_{2} \mathrm{O}$ being nonfrozen at -10 and $-5{ }^{\circ} \mathrm{C}$. $\mathrm{LiOH}(\mathrm{aq})$ has, however, a lower freezing point than both $\mathrm{NaOH}(\mathrm{aq})$ and $\mathrm{KOH}(\mathrm{aq})$ (Washburn 1926), which indicates that the addition of MCC impacts the freezing behaviour of water. This is further strengthened by the detected amount of dissolved MCC shown to decrease with temperature and at $5{ }^{\circ} \mathrm{C}$ passing the maximum amount mark. The same phenomenon of a decreasing amount of dissolved MCC at increased temperature could also be observed in $\mathrm{KOH}(\mathrm{aq})$, which is, however, more likely due to a decreasing dissolution capacity of the solvent with increasing temperature since $\mathrm{KOH}(\mathrm{aq})$ exhibits the lowest freezing-point depression of the three solvents. Interestingly, this was not the case for $\mathrm{NaOH}(\mathrm{aq})$ as the amount of dissolved MCC measured only changed slightly with increasing temperature, which could be an indication of the amount dissolved MCC and non-frozen $\mathrm{H}_{2} \mathrm{O}$ changing simultaneously and that $\mathrm{NaOH}(\mathrm{aq})$ is a more effective solvent for cellulose within this temperature range in comparison to $\mathrm{KOH}(\mathrm{aq})$.

The $\mathrm{NaOH}(\mathrm{aq})$ solvent comprising in addition 2.5 M urea manifested a similar MCC integral at -15 , -5 and $5{ }^{\circ} \mathrm{C}$ as $\mathrm{NaOH}(\mathrm{aq})$ at all temperatures and $\mathrm{LiOH}(\mathrm{aq})$ at $5{ }^{\circ} \mathrm{C}$ due to the fact that this sample never froze at $-20{ }^{\circ} \mathrm{C}$ (data not shown). Doubling the amount of MCC to $0.8 \mathrm{M}$ in $\mathrm{NaOH}(\mathrm{aq})$ resulted in a MCC integral comparable to $0.4 \mathrm{M}$, which suggests the system to be less effective at higher concentrations but this could also be an effect of the very high viscosity in this system that hampers the dissolved MCC to be detected (data not shown).

In addition, we recorded ${ }^{13} \mathrm{C}$ NMR spectra for MCC in $\mathrm{LiOH}(\mathrm{aq}), \mathrm{NaOH}(\mathrm{aq})$ and $\mathrm{KOH}(\mathrm{aq})$ at -5 and $5{ }^{\circ} \mathrm{C}$, which enables the detection of each carbon in the MCC monomeric unit $\beta$-glucopyranoside (Fig. 2). These results match with the observations from the ${ }^{1} \mathrm{H}$ spectra although no efforts have been made to enable a quantitative comparison. The MCC peaks for LiO$\mathrm{H}(\mathrm{aq})$ (red) and $\mathrm{NaOH}(\mathrm{aq})$ (black) are equally strong at -5 and $5{ }^{\circ} \mathrm{C}$ while for $\mathrm{KOH}(\mathrm{aq})$, the peaks are barely visible, although present, which indicates a lower amount of MCC dissolved in $\mathrm{KOH}(\mathrm{aq})$. The ${ }^{13} \mathrm{C}$ signal intensity seems to increase with increasing temperature for $\mathrm{LiOH}(\mathrm{aq})$ and $\mathrm{NaOH}(\mathrm{aq})$, which is in agreement with the results obtained from the 1D integrals.

No external chemical shift reference could be used, which allows only a qualitatively comparison of the chemical shift. However, the ${ }^{13} \mathrm{C}$ chemical shift observed in $\mathrm{NaOH}(\mathrm{aq})$ matched with the chemical shifts reported for dissolved cellulose in $\mathrm{NaOH}(\mathrm{aq})$ by Alves et al. (2016) but are for all carbons approximately 2 ppm lower compared to ${ }^{13} \mathrm{C}$ chemical shifts published by Isogai (1997), who studied MCC with DP 15 in $20 \% \mathrm{NaOH}(\mathrm{aq})$ in comparison to $8 \%$. There was a minor chemical shift change for position C6 with temperature to larger chemical shift values in $\mathrm{LiOH}(\mathrm{aq})$ and $\mathrm{NaOH}(\mathrm{aq})$ while the chemical shift values differed slightly for position $\mathrm{C} 1, \mathrm{C} 2, \mathrm{C} 3, \mathrm{C} 5$ and $\mathrm{C} 6$ in $\mathrm{LiOH}(\mathrm{aq})$ compared to $\mathrm{NaOH}(\mathrm{aq})$, which

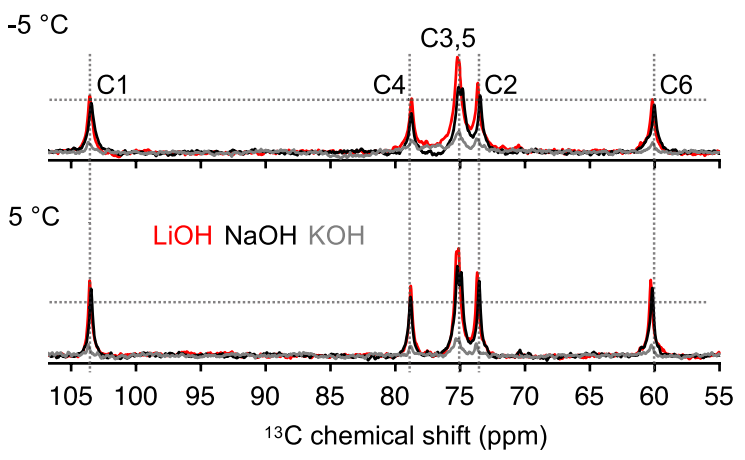

Fig. 2 1D non-scaled ${ }^{13} \mathrm{C}$ NMR spectra for MCC in LiOH(aq), $\mathrm{NaOH}(\mathrm{aq})$ and $\mathrm{KOH}(\mathrm{aq})$ recorded at -5 and $5{ }^{\circ} \mathrm{C}$. The gray dashed lines are positioned at the same amplitude in both spectra and are a guide to the eye 
suggests that the dissolved MCC is similar on an atomic level in all solvents.

Mean $T_{1} \mathrm{~s}$ for MCC and non-frozen water are converted to mean spin-lattice relaxation rates $R_{1} \mathrm{~s}$ by $1 / T_{1}$. An Arrhenius plot showed that the mean spinlattice relaxation rates $R_{1}$ of non-frozen water in $\mathrm{LiOH}(\mathrm{aq}), \mathrm{NaOH}(\mathrm{aq})$ and $\mathrm{KOH}(\mathrm{aq})$ followed a straight line (Fig. 3a). For LiOH(aq), the line manifested the steepest slope while for $\mathrm{KOH}(\mathrm{aq})$, the slope was the lowest. Interestingly, the Arrhenius behaviour for water was similar upon the addition of MCC. The observed temperature dependence for $\mathrm{NaOH}(\mathrm{aq})$ agrees with Yamashiki et al. (1988) although they reported on a stronger impact on $R_{1}$ upon the addition of cellobiose. The $T_{1}$ is sensitive to motions and fluctuations on the nanosecond timescale, which, when present, shorten the $T_{1}$ (Levitt 2008). However,
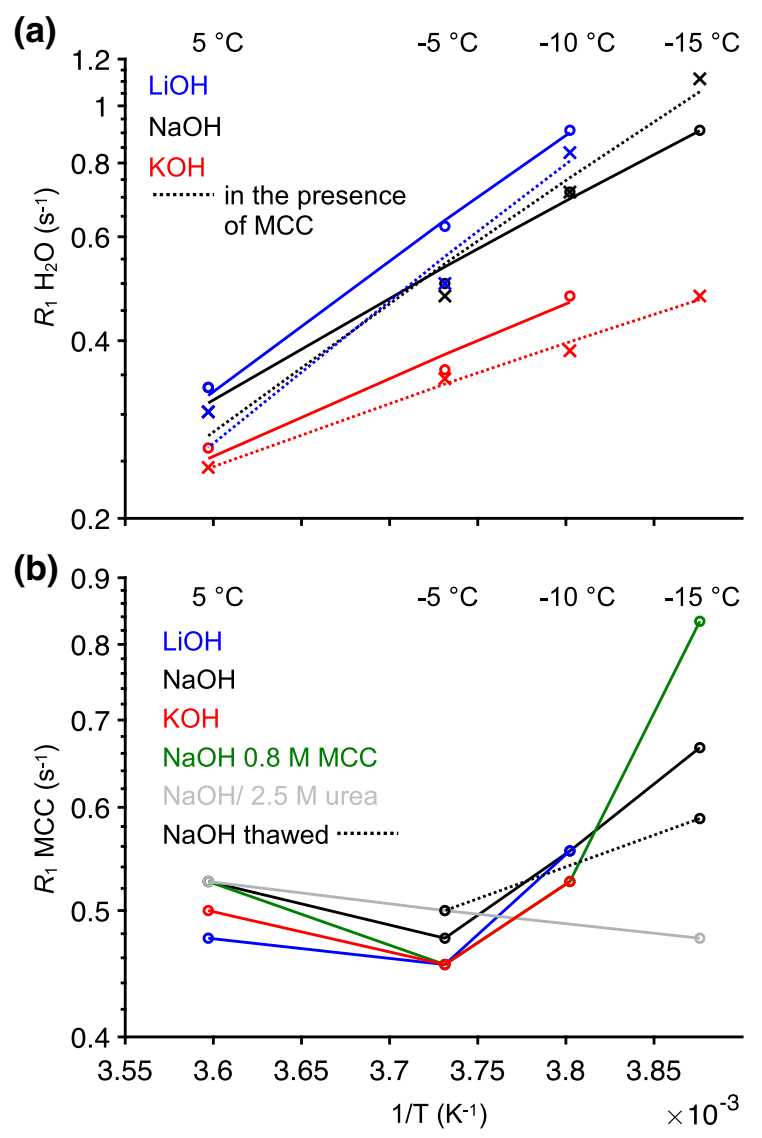

Fig. 3 Arrhenius plot of the mean $R_{1}$ of $\mathrm{H}_{2} \mathrm{O}$ (a) and $\mathrm{MCC}$ (b) as a function of temperature. In $\mathbf{a}$, the straight lines represent the data points fitted to a pseudo-Arrhenius behaviour while in b the lines are guides to the eye the addition of MCC seems to not impact the water motions in that regime.

Non-frozen water exhibited the longest $T_{1}$ in $\mathrm{KOH}(\mathrm{aq})$ and the shortest in $\mathrm{LiOH}(\mathrm{aq})$. For small molecules such as water, which are characterised by rotational correlation times of less than a $1 \mathrm{~ns}, T_{1}$ increases and $R_{1}$ decreases with increasing temperature, which is in agreement with our findings. In contrast, the $R_{1}$ of the MCC arrived at a plateau at $-5{ }^{\circ} \mathrm{C}$ for the $\mathrm{LiOH}(\mathrm{aq}), \mathrm{NaOH}(\mathrm{aq}), \mathrm{KOH}(\mathrm{aq})$ and $\mathrm{NaOH}(\mathrm{aq})$ with $0.8 \mathrm{M}$ MCC instead of $0.4 \mathrm{M}$ (Fig. 3b). In addition, an already thawed $\mathrm{NaOH}(\mathrm{aq})$ system followed the trend for the measured temperatures, -15 and $-5^{\circ} \mathrm{C}$. For $\mathrm{NaOH}(\mathrm{aq}) / 2.5 \mathrm{M}$ urea (gray), the plateau appeared to be below $-15^{\circ} \mathrm{C}$, which might be explained by this system still being liquid like at this temperature.

The parameter $T_{2}$ is instead an indicator of motions and fluctuations occurring on the millisecond timescale (Levitt 2008). Here, we normalised the mean $T_{2}$ of non-frozen water in $\mathrm{LiOH}(\mathrm{aq}), \mathrm{NaOH}(\mathrm{aq})$ and $\mathrm{KOH}(\mathrm{aq})$ with the addition of $\mathrm{MCC}$ by the mean $T_{2}$ of the reference solutions. For $\mathrm{LiOH}(\mathrm{aq})$, the normalised $T_{2}$ of water stayed constant while for $\mathrm{KOH}(\mathrm{aq})$ the normalised $T_{2}$ increased with temperature (Fig. 4, blue and black). The addition of MCC to $\mathrm{KOH}(\mathrm{aq})$ influenced the mean $T_{2}$ the most. The $T_{2} \mathrm{~s}$ are most likely affected by the exchange of the water molecules with the hydroxyl groups on the dissolved MCC and with the water that is associated with the semi-rigid MCC discussed in the next part. The mean

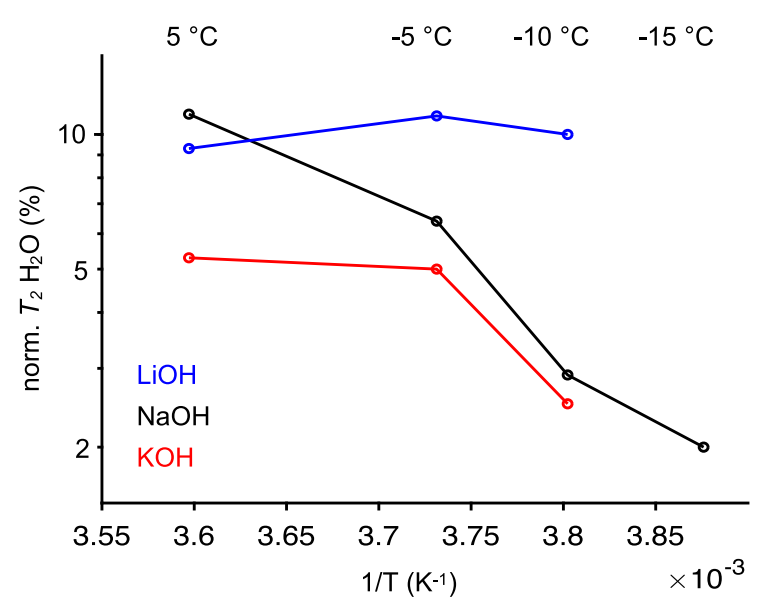

Fig. 4 Arrhenius plot of mean $T_{2}$ of $\mathrm{H}_{2} \mathrm{O}$ in $\mathrm{LiOH}(\mathrm{aq})$ (blue), $\mathrm{NaOH}(\mathrm{aq})$ (black) and $\mathrm{KOH}(\mathrm{aq})$ (red) normalised by the $T_{2}$ of the reference solutions as a function of temperature 
$T_{2}$ of the dissolved MCC is on the order of a couple of tens of milliseconds, hampering an accurate estimation.

Semi-rigid cellulose

In other research fields, magnetisation transfer (MT) NMR experiments have been used to estimate the exchange rates of $\mathrm{H}_{2} \mathrm{O}$ with mobile/exchangeable protons present in $\mathrm{OH}$ - or $\mathrm{NH}_{2}$-groups, which resonate close to the water peak in a ${ }^{1} \mathrm{H}$ NMR spectrum and are only visible when exchanging slower than approximately $100 \mathrm{~Hz}$. Furthermore, MT NMR is able to observe protons associated to semi-rigid polymers or tissues, which are invisible for conventional ${ }^{1} \mathrm{H}$ NMR due to their short $T_{2}$ s (Zaiss et al. 2015). Bulk water molecules exchanging with "bound and immobile" water molecules on semi-rigid cellulose are illustrated in Fig. 5. With "bound and immobile" water molecules, we mean water molecules that keep associated with the semi-rigid cellulose for timescales shorter than the exchange rate $k_{\text {off }}$. The invisible signal of "bound and immobile" water molecules and the semirigid cellulose might cover a ppm range of 10-150 ppm, too broad to be detected because of short $T_{2} \mathrm{~s}$ and homonuclear dipolar couplings, which might be up to $70 \mathrm{kHz}$. When irradiating the invisible signal, the "bound and immobile" water molecules will transfer their magnetisation to the bulk water molecules if there is an exchange not faster than approximately $10^{3} \mathrm{~Hz}$ (Anthis and Clore 2015). As a result, the bulk water molecules become saturated and the intensity of the water peak will decrease.

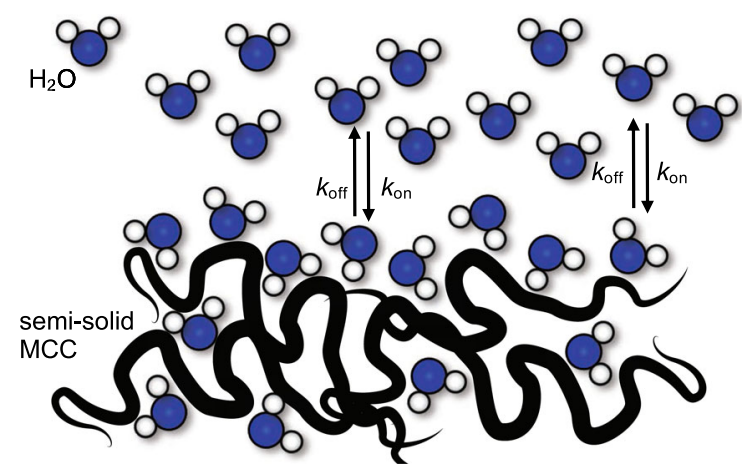

Fig. 5 Schematic illustration of "bound and immobile" water molecules to semi-rigid MCC exchanging with bulk water on the $k_{\text {on }}$ and $k_{\text {off }}$ timescale
Hence, an MT spectrum or a so called Z-spectrum displays the intensity of the water peak as a function of the irradiation frequency denoted offset as it is the frequency offset from the water peak, which is set to 0 ppm. A ${ }^{1} \mathrm{H}$ NMR spectrum of $\mathrm{LiOH}(\mathrm{aq})$ with the addition of $\mathrm{MCC}$ at $5{ }^{\circ} \mathrm{C}$ is shown in Fig. 6a, where the water peak is set to $0 \mathrm{ppm}$. If there would be an exchange process occurring at a rate slower than approximately $10^{3} \mathrm{~Hz}$ between water molecules and the hydroxyl groups of MCC, whose H1-H6 peaks resonate here at negative ppm values while the hydroxyl groups would appear at positive ppm values, the $Z$-spectrum would show a dip at the position where the exchange happens. We expect, however, the exchange rate at this high $\mathrm{pH}$ in alkali to be much faster (Zhou and van Zijl 2006), which explains why the $Z$-spectra lack these features (see Fig. $6 b-d$ ).

Instead, the $Z$-spectra showed different shapes and widths for $\mathrm{LiOH}(\mathrm{aq})$ (b), $\mathrm{NaOH}(\mathrm{aq})$ (c) and $\mathrm{KOH}(\mathrm{aq})$ (d) at $-10,-5$ and $5{ }^{\circ} \mathrm{C}$. The width, which we here attribute to the swollen state of semi-rigid MCC, depends mainly on the $1 / T_{2}$ of the protons associated to the semi-solid fraction (Sled 2018). At $-10{ }^{\circ} \mathrm{C}$, the width was similarly broad for $\mathrm{NaOH}(\mathrm{aq})$ and $\mathrm{KOH}(\mathrm{aq})$ while for $\mathrm{LiOH}(\mathrm{aq})$, the width was much smaller suggesting that the semi-solid MCC is swollen to a greater extent for $\mathrm{LiOH}$. The broadening of the curve started first above 0.2 of the normalised intensity, indicating that the fraction of semi-rigid MCC for $\mathrm{LiOH}(\mathrm{aq})$ is less compared to $\mathrm{KOH}(\mathrm{aq})$ and $\mathrm{NaO}$ $\mathrm{H}(\mathrm{aq})$. For $\mathrm{LiOH}(\mathrm{aq})$, the fraction rather than the width changed with temperature. A similar behaviour was found for $\mathrm{KOH}(\mathrm{aq})$ although the normalised intensity stayed constant when increasing the temperature from -5 to $5{ }^{\circ} \mathrm{C}$. At $5{ }^{\circ} \mathrm{C}$, there was still a broad feature visible, which agrees with the ${ }^{1} \mathrm{H}$ integrals revealing a fraction of non-dissolved MCC with the largest fraction for $\mathrm{KOH}(\mathrm{aq})$. Interestingly, we observed a dip at above $60 \mathrm{ppm}$ for all Z-spectra at $-5^{\circ} \mathrm{C}$, which needs to be further investigated as no explanation was found here. For $\mathrm{NaOH}(\mathrm{aq})$, both normalised intensity and width changed with increasing temperature, which might indicate that the semi-rigid MCC swelled to a greater extent from -5 to $5{ }^{\circ} \mathrm{C}$. This result might be related to the reported decrease of the intrinsic viscosity of cellulose in the $\mathrm{NaOH}(\mathrm{aq})$ system with increasing temperature (Roy et al. 2003; Kamide et al. 
(a)

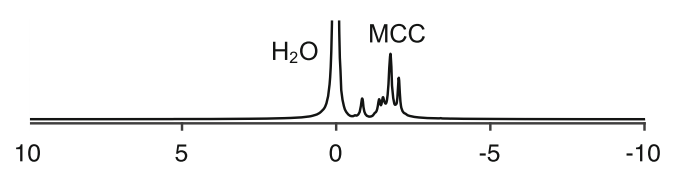

(b)

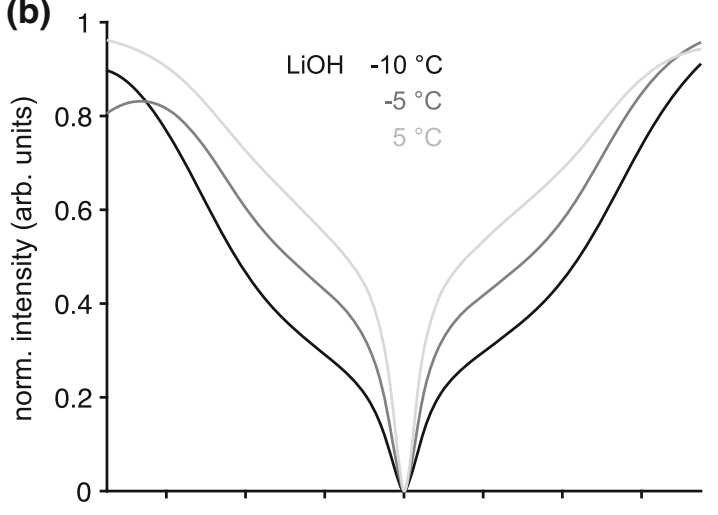

(c)

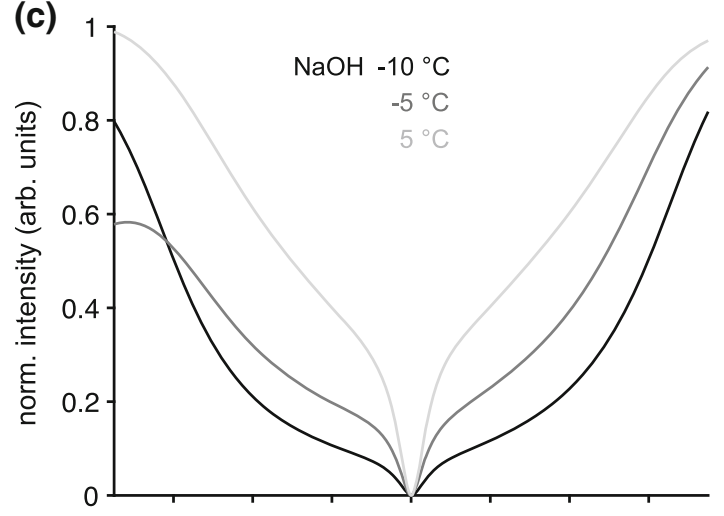

(d)

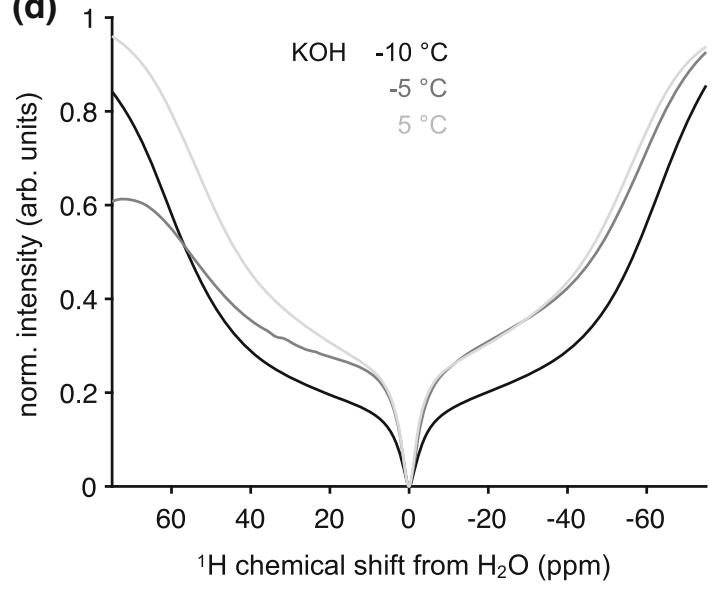

Fig. $61 \mathrm{D}{ }^{1} \mathrm{H}$ spectrum of $\mathrm{LiOH}(\mathrm{aq})$ with the addition of MCC (a). MT (Z-)spectra for $\mathrm{LiOH}(\mathrm{aq})$ (b), $\mathrm{NaOH}(\mathrm{aq})$ (c) and $\mathrm{KOH}(\mathrm{aq})(\mathbf{d})$ as a function of temperature. The chemical shift scale is normalised to the water peak, which is set to $0 \mathrm{ppm}$
1987) although shearing might affect the cellulose structure.

In general, the shape and width of the $Z$-spectrum depends, however, on many parameters such as the exchange rate $k_{\text {on }}$ and $k_{\text {off }}$ as well as $T_{1}$ and $T_{2}$ of water and the semi-rigid MCC, the water and semi-rigid MCC fractions, the saturation duration and the $B_{1}$ field of the saturation RF pulse. Changing the saturation duration and $B_{1}$ field of the saturation would allow extracting $k_{\text {on }}$ and $k_{\text {off }}$ and details about the exchange of water molecules with the semi-rigid MCC and the semi-rigid MCC itself. We foresee that MT NMR could most likely contribute to elucidate recent modelling results such as if the concentration of water is higher around the hydroxyl groups (Stenqvist et al. 2015 ) or that there is more tightly coordinated water structure close to the microfibrillar cellulose chains (Hadden et al. 2013). However, this is out of the scope for this work and part of future studies. The clear distinction in dissolution capacity between $\mathrm{NaOH}(\mathrm{aq})$ and $\mathrm{KOH}(\mathrm{aq})$ falls in line with the phenomenon of a so-called reversed Hofmeister series (Sivan 2016). In the case of a normal Hofmeister series, ions of a certain bare ionic radius are considered as hydrophilic or hydrophobic. $\mathrm{Li}^{+}$and $\mathrm{Na}^{+}$are considered hydrophilic and strongly hydrated while $\mathrm{K}^{+}$is considered as hydrophobic and weakly hydrated. This means that when a hydrophobic surface, such as a hydrophobic surface of the amphiphilic cellulose, is introduced in the solvent, the more hydrophobic $\mathrm{K}^{+}$ion will accumulate on the surface to minimise its free energy while $\mathrm{Li}^{+}$and $\mathrm{Na}^{+}$remains associated with the solvent which is energetically the most favourable state for a hydrophilic ion. However, in the case of a reversed Hofmeister series, the hydrophobic surface is considered to be deprotonated due to an increase in $\mathrm{pH}$, e.g. the hydroxyl groups on cellulose become deprotonated. Deprotonation of the surface increases its hydrogen bonding with $\mathrm{H}_{2} \mathrm{O}$, which in turn will lead to an expulsion of the $\mathrm{K}^{+}$ion from the surface as $\mathrm{H}_{2} \mathrm{O}$ and strongly hydrated ions, such as $\mathrm{Li}^{+}$and $\mathrm{Na}^{+}$, minimise their free energy when binding to the surface (Sivan 2016). In other words, deprotonation in combination with sufficient binding of water, both by the cellulose and the ions present, could be an explanation for the difference in dissolution capacity of cold aqueous alkalis. 


\section{Conclusions}

When comparing the dissolution process of $\mathrm{MCC}$ in equimolar solutions based on $\mathrm{LiOH}(\mathrm{aq}), \mathrm{NaOH}(\mathrm{aq})$ and $\mathrm{KOH}(\mathrm{aq})$, we found that $\mathrm{KOH}(\mathrm{aq})$ dissolved up to $25 \%$ of the maximum amount of MCC while $\mathrm{LiOH}(\mathrm{aq})$ and $\mathrm{NaOH}(\mathrm{aq})$ dissolved up to $70 \%$ without stirring. Fast bulk water dynamics were not affected by the addition of MCC. The spin-lattice relaxation rates of dissolved MCC as a function of temperature exhibited a plateau at $-5{ }^{\circ} \mathrm{C}$ for all solvent systems except for $\mathrm{NaOH} / 2.5 \mathrm{M}$ urea, which revealed a plateau shifted to lower temperatures. MT NMR spectra reported on a different behaviour for the semi-rigid MCC when increasing temperature for $\mathrm{LiOH}(\mathrm{aq})$, $\mathrm{NaOH}(\mathrm{aq})$ and $\mathrm{KOH}(\mathrm{aq})$. The semi-rigid $\mathrm{MCC}$ appeared swollen to a greater extent for $\mathrm{LiOH}(\mathrm{aq})$ compared to $\mathrm{KOH}(\mathrm{aq})$ while for $\mathrm{NaOH}(\mathrm{aq})$ the swollen state changed from -5 to $5{ }^{\circ} \mathrm{C}$. In conclusion, we present here an NMR methodology, which monitors water exchanges dynamics associated with the semi-rigid cellulose and the swollen state of the semi-rigid cellulose, which might play a crucial role for understanding the cellulose dissolution mechanism in cold aqueous alkali. To gain further insight, MT parameters need to be varied in a systematic matter, which is out of the scope of this work.

Acknowledgments Open access funding provided by Chalmers University of Technology. This work has been carried out as a part of the framework of Avancell - Center for Fiber Engineering, which is a research collaboration between Södra Innovation and Chalmers University of Technology. The author thanks the Södra Skogsägarnas Foundation for Research, Development and Education for their financial support. The Swedish NMR Center is acknowledged for spectrometer time.

\section{Compliance with ethical standards}

Conflict of interest The authors declare that they have no conflict of interest.

Open Access This article is distributed under the terms of the Creative Commons Attribution 4.0 International License (http:// creativecommons.org/licenses/by/4.0/), which permits unrestricted use, distribution, and reproduction in any medium, provided you give appropriate credit to the original author(s) and the source, provide a link to the Creative Commons license, and indicate if changes were made.

\section{References}

Alves L, Medronho B, Antunes FE, Topgaard D, Lindman B (2016) Dissolution state of cellulose in aqueous systems. 1. Alkaline solvents Cellul 23(1):247-258. https://doi.org/10. 1007/s10570-015-0809-6

Anthis NJ, Clore GM (2015) Visualizing transient dark states by NMR spectroscopy. Q Rev Biophys 48(1):35-116. https:// doi.org/10.1017/S0033583514000122

Bialik E, Stenqvist B, Fang Y, Östlund Å, Furó I, Lindman B, Lund M, Bernin D (2016) Ionization of cellobiose in aqueous alkali and the mechanism of cellulose dissolution. J Phys Chem Lett 7(24):5044-5048. https://doi.org/10. 1021/acs.jpclett.6b02346

Budtova T, Navard P (2016) Cellulose in $\mathrm{NaOH}$-water based solvents: a review. Cellulose 23(1):5-55. https://doi.org/ 10.1007/s10570-015-0779-8

Cai J, Zhang L (2005) Rapid dissolution of cellulose in LiOH/ urea and $\mathrm{NaOH} /$ urea aqueous solutions. Macromol Biosci 5(6):539-548. https://doi.org/10.1002/mabi.200400222

Davidson G (1937) The dissolution of chemically modified cotton cellulose in alkaline solutions. Part 3-In solutions of sodium and potassium hydroxide containing dissolved zinc, beryllium and aluminium oxides. J Text Inst Trans 28(2):T27-T44. https://doi.org/10.1080/194470237086 31789

Davidson GF (1934) The dissolution of chemically modified cotton cellulose in alkaline solutions. Part I-In solutions of sodium hydroxide, particularly at temperatures below the normal. J Text Inst Trans 25(5):T174-T196. https://doi. org/10.1080/19447023408661621

Gunnarsson M, Bernin D, Hasani M (2019) Capturing of $\mathrm{CO}_{2}$ in $\mathrm{NaOH}(\mathrm{aq})$ in the presence of urea and methyl $\beta$-glucopyranoside. Manuscript submitted for publication

Gustavsson S, Alves L, Lindman B, Topgaard D (2014) Polarization transfer solid-state NMR: a new method for studying cellulose dissolution. RSC Adv 4(60):31836-31839. https://doi.org/10.1039/C4RA044 $15 \mathrm{~K}$

Hadden JA, French AD, Robert J, Rj Woods (2013) Unraveling cellulose microfibrils: a twisted tale. Biopolymers 10:746-756

Hagman J, Gentile L, Moestrup Jessen C, Behrens M, Bergqvist $\mathrm{KE}$, Olsson U (2017) On the dissolution state of cellulose in cold alkali solutions. Cellulose 24:2003-2015

Isogai A (1997) NMR analysis of cellulose dissolved in aqueous $\mathrm{NaOH}$ solutions. Cellulose 4(2):99-107. https://doi.org/10. 1023/A:1018471419692

Kamide K, Saito M, Kowsaka K (1987) Temperature dependence of limiting viscosity number and radius of gyration for cellulose dissolved in aqueous $8 \%$ sodium hydroxide solution. Polym J 19:1173-1181

Levitt M (2008) Spin dynamics: basics of nuclear magnetic resonance, 2 nd edn

Liebert T (2010) Cellulose solvents-remarkable history, bright future. In: Cellulose solvents: for analysis, shaping and chemical modification, chap 1, pp 3-54. https://doi.org/10. 1021/bk-2010-1033.ch001

Lilienfeld L (1924) Manufacture of cellulose solution. British patent no. 212864 
Lindman B, Karlström G, Stigsson L (2010) On the mechanism of dissolution of cellulose. J Mol Liq 156(1):76-81. https:// doi.org/10.1016/j.molliq.2010.04.016

Medronho B, Lindman B (2014) Competing forces during cellulose dissolution: from solvents to mechanisms. Curr Opin Colloid Interface Sci 19(1):32-40. https://doi.org/10.1016/ j.cocis.2013.12.001

Medronho B, Romano A, Miguel M, Stigsson L, Lindman B (2012) Rationalizing cellulose (in)solubility: reviewing basic physicochemical aspects and role of hydrophobic interactions. Cellulose 19(3):581-587. https://doi.org/10. 1007/s10570-011-9644-6

Roy C, Budtova T, Navard P (2003) Rheological properties and gelation of aqueous cellulose $\mathrm{NaOH}$ solutions. Biomacromolecules 4(2):259-264. https://doi.org/10.1021/ bm020100s

Sivan U (2016) The inevitable accumulation of large ions and neutral molecules near hydrophobic surfaces and small ions near hydrophilic ones. Curr Opin Colloid Interface Sci 22:1-7. https://doi.org/10.1016/j.cocis.2016.02.004

Sled JG (2018) Modelling and interpretation of magnetization transfer imaging in the brain. Neuroimage 182:128-135. https://doi.org/10.1016/j.neuroimage.2017.11.065

Sobue H, Kiessig H, Hess K (1939) The system: cellulosesodium hydroxide-water in relation to the temperature. Z Physik Chem B 43:309-328

Stenqvist B, Wernersson E, Lund M (2015) Cellulose-water interactions: effect of electronic polarizability. Nord Pulp Pap Res J 30:26-31

Tata GM (1980) Theoretical principles of inorganic chemistry. McGraw-Hill Education

Washburn EW (1926) Freezing-point lowering of aqueous solutions. Knovel

Xiong B, Zhao P, Cai P, Zhang L, Hu K, Cheng G (2013) NMR spectroscopic studies on the mechanism of cellulose dissolution in alkali solutions. Cellulose 20(2):613-621. https://doi.org/10.1007/s10570-013-9869-7

Yamashiki T, Kamide K, Okajima K, Kowsaka K, Matsui T, Fukase H (1988) Some characteristic features of dilute aqueous alkali solutions of specific alkali concentration $\left(2.5 \mathrm{~mol} \mathrm{~L}^{-1}\right)$ which possess maximum solubility power against cellulose. Polym J 20(6):447-457. https://doi.org/ 10.1295/polymj.20.447

Yang Q, Qi H, Lue A, Hu K, Cheng G, Zhang L (2011) Role of sodium zincate on cellulose dissolution in $\mathrm{NaOH} / \mathrm{urea}$ aqueous solution at low temperature. Carbohydr Polym 83(3):1185-1191. https://doi.org/10.1016/j.carbpol.2010. 09.020

Zaiss M, Zu Z, Xu J, Schuenke P, Gochberg DF, Gore JC, Ladd ME, Bachert P (2015) A combined analytical solution for chemical exchange saturation transfer and semi-solid magnetization transfer. NMR Biomed 28(2):217-230. https://doi.org/10.1002/nbm.3237

Zhang L, Ruan D, Gao S (2002) Dissolution and regeneration of cellulose in $\mathrm{NaOH} /$ thiourea aqueous solution. J Polym Sci Part B Polym Phys 40(14):1521-1529. https://doi.org/10. 1002/polb.10215

Zhou J, van Zijl PCM (2006) Chemical exchange saturation transfer imaging and spectroscopy. Prog Nucl Magn Reson Spectrosc 48(2):109-136. https://doi.org/10.1016/j.pnmrs. 2006.01.001

Zhou J, Zhang L, Cai J (2004) Behavior of cellulose in NaOH/ Urea aqueous solution characterized by light scattering and viscometry. J Polym Sci Part B Polym Phys 42(2):347-353. https://doi.org/10.1002/polb.10636

Publisher's Note Springer Nature remains neutral with regard to jurisdictional claims in published maps and institutional affiliations. 